\title{
Synthesis, Characterization, and Electrochemical Study of Tetradentate Ruthenium-Schiff Base Complexes: Dioxygen Activation with a Cytochrome P450 Model Using 1- or 2-Methylimidazole as Axial Bases
}

\author{
Ali Ourari, ${ }^{1}$ Mostefa Khelafi, ${ }^{1}$ Djouhra Aggoun, ${ }^{1}$ Gilles Bouet, ${ }^{2}$ and Mustayeen A. Khan ${ }^{2}$ \\ ${ }^{1}$ Laboratoire d'Électrochimie, d'Ingénierie Moléculaire et de Catalyse Rédox (LEIMCR), Faculté des Sciences de l'Ingénieur, \\ Université Ferhat Abbas, Sétif 19000, Algeria \\ ${ }^{2}$ SONAS, EA 921, Faculté de Pharmacie, Université d'Angers 16 Boulevard Daviers, 49045 Angers Cedex 01, France
}

Correspondence should be addressed to Ali Ourari, alourari@yahoo.fr

Received 18 September 2010; Revised 21 December 2010; Accepted 22 March 2011

Academic Editor: Milan M. Jaksic

Copyright (C) 2011 Ali Ourari et al. This is an open access article distributed under the Creative Commons Attribution License, which permits unrestricted use, distribution, and reproduction in any medium, provided the original work is properly cited.

Salicylaldehyde, 2-hydroxyacetophenone, and 3,5-dichlorosalicylaldehyde react with 1,2-diaminoethane to give three symmetrical Schiff bases $\mathrm{H}_{2} \mathrm{~L}^{1}, \mathrm{H}_{2} \mathrm{~L}^{2}$, and $\mathrm{H}_{2} \mathrm{~L}^{3}$, respectively. With $\mathrm{Ru}(\mathrm{III})$ ions, these ligands lead to three complexes: $\mathrm{Ru}$ (III)ClL ${ }^{1}$ (1), $\mathrm{Ru}(\mathrm{III}) \mathrm{ClL}^{2}$ (2), and $\mathrm{Ru}(\mathrm{III}) \mathrm{ClL}^{3}$ (3). The purity of these compounds was estimated by TLC technique and microanalysis while their structures were supported by the usual spectroscopic methods such as NMR, infrared, and electronic spectra. The cyclic voltammetry in acetonitrile showed irreversible waves for all three ligands. Under the same experimental conditions, it was proved that the ruthenium is coordinated in the three complexes 1,2 , and 3 showing quasireversible redox systems. The behavior of these complexes and their comparison with cytochrome P450 are investigated using them as catalysts in the presence of molecular oxygen with an apical nitrogen base: 1- or 2-methylimidazole.

\section{Introduction}

During the last decade, the tetradentate Schiff base complexes of transition metals have been extensively studied mainly with manganese, iron, cobalt, copper, and nickel [1-5] while those of ruthenium are relatively less studied [6]. Thus, it was demonstrated that such materials might be involved in several applications such as in catalysis [7] or electrocatalysis [8] by activating many small molecules like carbon dioxide [9] or molecular oxygen [10]. Here, we focus on the electrochemical study and the activation of molecular oxygen using the tetradentate ruthenium-Schiff base complexes, in order to substantially reduce its reduction potential, leading to electrocatalytic systems operating at lower potential values. So, the metabolic role of cytochrome P450 is well known [11] and its metabolic cycle is established [12]. In some steps, molecular dioxygen fixation, water elimination, and peroxo high oxidation state metal (i.e.,
$\mathrm{Fe}^{\mathrm{IV}}$ ) and so forth, are involved In all cases, the active form of the coordinated iron ion is axially linked to a sulfur protein. Therefore, a large number of cytochrome P450 oxocomplexes, including the nonporphyrinic ligands such as Schiff base complexes, have been tested for their catalytic activity [13-17] and their electrocatalytic properties $[8,17-26]$. Thus, new catalysts deriving from symmetrical tetradentate ruthenium-Schiff base complexes seem to be more and more attractive and efficient in catalysis [27, 28]. These new electrocatalytic systems have been less studied than those currently applied in catalysis [6].

Manganese(III), iron(III), cobalt(II), and ruthenium(III)Schiff base complexes are mainly used in indirect electroreductions of halohydrocarbons $[29,30]$ or molecular oxygen [31-36] in order to epoxide olefins or to oxidize hydrocarbons. These reactions using electrocatalytic systems could be performed in homogeneous as well as in heterogeneous catalysis. This second case concerns the elaboration 
of modified electrodes (ME) by covalent grafting of pyrrole or thiophene moieties via the etherification [37] or esterification [38] reactions involving a phenolic group. These materials for electrodes may also be used as amperometric sensors to detect various species: molecular dioxygen [39-42] and biomolecules like glucose [43-45]. Several studies have demonstrated the high efficiency of these electrocatalytic systems when operating in heterogeneous catalysis in a chemical-electrochemical pathway using modified electrodes based mainly upon organic polymer films containing the complex species covalently grafted as catalyst $[35,38,46]$.

In this work, three complexes with ruthenium(III) ions are synthesized (Scheme 1) and characterized. Our main aim is to study these complexes as catalysts by cyclic voltammetry in the presence of molecular oxygen and of two axial bases; 1 methylimidazole and its position isomer 2-methylimidazole. Thus, the electrophile character on the metallic center increases when the basicity of the axial base is higher leading to a prompt reaction between oxygen and metal. This electrocatalytic system model of cytochrome P450 is mainly studied in the activation of small molecules among them the molecular oxygen. This study might also be supported by further applications such as epoxidation of olefins or oxidation of hydrocarbons or for other applications.

\section{Experimental}

2.1. Physical Measurements. The ${ }^{1} \mathrm{H}$ NMR spectra of the ligands were recorded with a Bruker $\mathrm{AC} 300$ at $25^{\circ} \mathrm{C}$ in $\mathrm{DMSO}^{-\mathrm{D}_{6}}$ as solvent. All chemical shifts are given in ppm using tetramethylsilane (TMS) as internal reference. The IR spectra were recorded using a Perkin-Elmer 1000FTIR Spectrometer ( $\mathrm{KBr}$ discs). The UV-visible spectra were obtained with a Unicam UV-300 Spectrophotometer. The microanalysis was performed on "Microanalyseur Flash EA1112CHNS Thermoelectron" (Laboratoire des Sciences Chimiques, Rennes-1 University, France). Cyclic voltammograms were performed with a Tacussel PJT Potentiostat Galvanostat, driven by Pilovit-Num. All measurements were carried out in a $5 \mathrm{~mL}$ Metrohm monocompartment cell equipped with a conventional three-electrodes system. The electrodes were polished with diamond paste and rinsed with large amounts of acetone and finally with the solvent. The working electrode was a disc of glassy carbon $(5 \mathrm{~mm}$ diameter), the counter electrode was a platinum wire, and the reference electrode was a saturated calomel electrode (SCE), and all results are given versus SCE. The solvent was acetonitrile with a $10^{-3} \mathrm{~mol} \cdot \mathrm{L}^{-1}$ concentration for the studied complexes, and the ionic strength was maintained at $0.1 \mathrm{~mol} \cdot \mathrm{L}^{-1}$ with tetra-n-butylammonium perchlorate (TBAP).

2.2. Chemicals. Organic chemicals, solvents, and ruthenium chloride $\mathrm{RuCl}_{3} \cdot \mathrm{xH}_{2} \mathrm{O}$ were analytical grade, purchased from Aldrich France and used as received without any further purification except benzoic anhydride because it contains traces of benzoic acid. It was washed with aqueous solution $(10 \%, \mathrm{w} / \mathrm{w})$, a sodium hydrogencarbonate, and recrystallized from a toluene-petroleum ether by dropwise adding of petroleum ether to toluene solution until a neat trouble. Then, the product was left overnight in refrigerator and the solid was recovered by filtration and washed with petroleum ether.

2.3. Syntheses of the Ligands. The ligands were prepared as previously reported in the literature $[1,22-25] .60 \mathrm{mg}$ $(1 \mathrm{mmol})$ of diaminoethane in $\mathrm{EtOH}\left(8 \mathrm{~cm}^{3}\right)$ was added dropwise to $244 \mathrm{mg}$ ( $2 \mathrm{mmol}$ ) of salicylaldehyde or its derivatives $\left(\mathrm{EtOH}, 12 \mathrm{~cm}^{3}\right)$. The mixture was stirred under argon atmosphere at room temperature for 2 hours. In the case of 2-hydroxyacetophenone the reaction was carried out under refluxing conditions for the same time. The resulting product was kept overnight at $\mathrm{ca} .4^{\circ} \mathrm{C}$. The solid was filtered, washed several times with diethyloxide, and its purity was checked by TLC using a mixture of $\mathrm{CH}_{2} \mathrm{Cl}_{2} / \mathrm{MeOH}(9 / 1, \mathrm{v} / \mathrm{v})$ as solvents.

Ligand $\mathrm{H}_{2} \mathrm{~L}^{1}\left(\mathrm{R}_{1}=\mathrm{H}, \mathrm{R}_{2}=\mathrm{H}\right)$ : solid with yellow color, $\mathrm{R}_{f}(0.64)$, yield $(70 \%),{ }^{1} \mathrm{H}$ nmr: $2 \mathrm{CH}_{2}-\mathrm{N}(4 \mathrm{H}, \mathrm{s}=3.87)$, $2 \mathrm{~N}=\mathrm{CH}(2 \mathrm{H}, \mathrm{s}=8.60), \mathrm{H}_{\text {arom. }}(8 \mathrm{H}, \mathrm{m}=7.21), \mathrm{OH}_{\text {phenol }}(2 \mathrm{H}$, $s=13.36)$.

Ligand $\mathrm{H}_{2} \mathrm{~L}^{2}\left(\mathrm{R}_{1}=\mathrm{CH}_{3}, \mathrm{R}_{2}=\mathrm{H}\right)$ : solid with yellow color, $\mathrm{R}_{f}(0.28)$, yield $(77 \%),{ }^{1} \mathrm{H}$ nmr: $2 \mathrm{CH}_{2}-\mathrm{N}(4 \mathrm{H}, \mathrm{s}=$ $3.90), 2 \mathrm{~N}=\mathrm{C}\left(\mathrm{CH}_{3}\right)(6 \mathrm{H}, \mathrm{s}=2.40), \mathrm{H}_{\text {arom. }}(8 \mathrm{H}, \mathrm{m}=7.26)$, $\mathrm{OH}_{\text {phenol }}(2 \mathrm{H}, \mathrm{s}=16.10)$.

Ligand $\mathrm{H}_{2} \mathrm{~L}^{3}\left(\mathrm{R}_{1}=\mathrm{H}, \mathrm{R}_{2}=\mathrm{Cl}\right)$ : solid with yellow color, $\mathrm{R}_{f}(0.20)$, yield (90\%), $\mathrm{C},{ }^{1} \mathrm{H} \mathrm{nmr}: 2 \mathrm{CH}_{2}-\mathrm{N}(4 \mathrm{H}, \mathrm{t}=4.00)$, $2 \mathrm{~N}=\mathrm{CH}(2 \mathrm{H}, \mathrm{s}=8.57), \mathrm{H}_{\text {arom. }}(4 \mathrm{H}, \mathrm{m}=6.91), \mathrm{OH}_{\text {phenol }}(2 \mathrm{H}$, $\mathrm{s}=12.71)$.

2.4. Preparation of the Complexes. The complexes were prepared as described in the literature [47] with a slight modification. A solution of the ligand $\mathrm{H}_{2} \mathrm{~L}^{n}(n=1,2,3)$ in absolute EtOH $\left(0.5 \mathrm{mmol}, 10 \mathrm{~cm}^{3}\right)$, containing two molar equivalents of $\mathrm{KOH}$, was added quickly to the ruthenium chloride, $0.5 \mathrm{mmol}$ dissolved in $5 \mathrm{~cm}^{3}$ of absolute EtOH. The mixture was heated for at least $12 \mathrm{~h}$ under argon atmosphere and kept overnight at $4^{\circ} \mathrm{C}$. The complex was filtered, washed several times with a $\mathrm{MeOH} / \mathrm{H}_{2} \mathrm{O}(1: 1, \mathrm{v} / \mathrm{v})$ mixture previously bubbled with $\mathrm{Ar}$ for 20-30 min (in order to avoid the oxygenation of the complex). Moreover, this operation was done as soon as possible in glove box under argon atmosphere for the same reasons. The purity of these complexes was checked by TLC under the same conditions as for the ligands.

\section{Results and Discussion}

The main analytical data for the complexes are given in Table 1.

3.1. Molecular Formulae. The elemental analysis (Table 1) indicated that the molecular formulae of our three complexes 1,2 , and 3 contain the potassium chloride $(\mathrm{KCl})$. These results are similar to those obtained by Taqui Khan et al. [47] because the experimental procedure is almost the same. For the mass spectroscopy analysis, it has only given some fragments without the expected molecular peaks as it was mentioned in the literature $[48,49]$. 


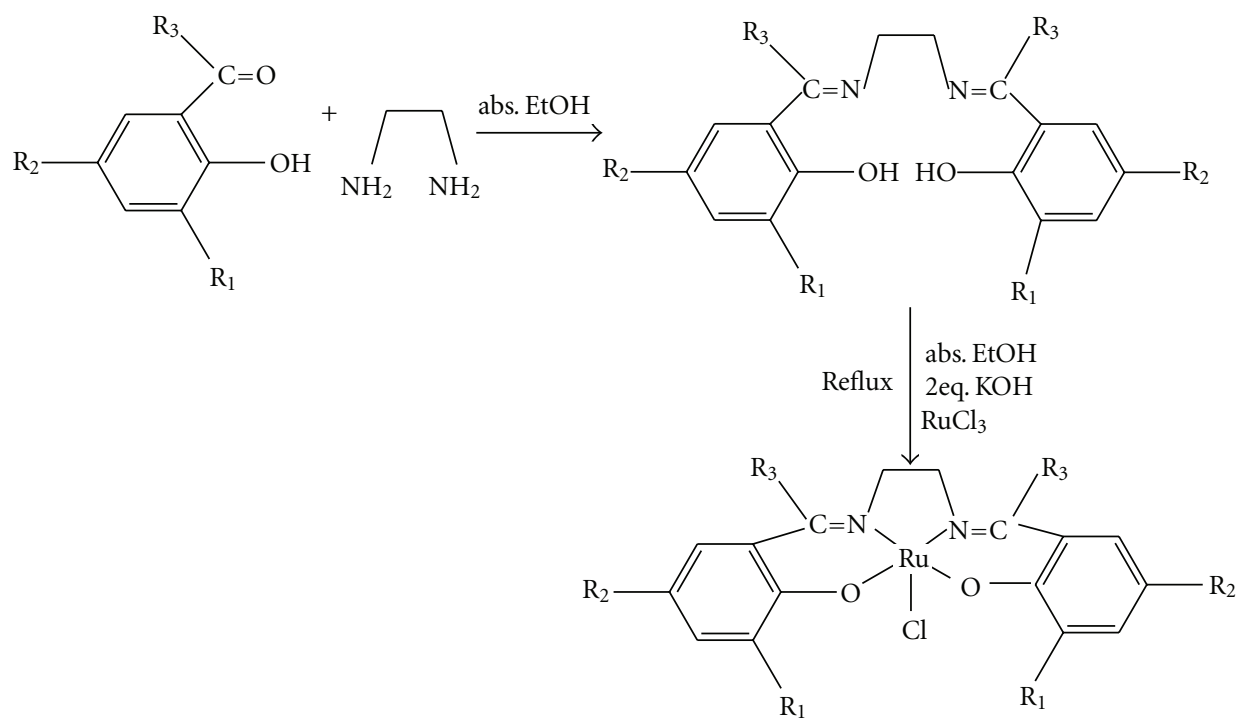

(1) $\mathrm{R}_{1}=\mathrm{R}_{2}=\mathrm{R}_{3}=\mathrm{H}$
(2) $\mathrm{R}_{1}=\mathrm{R}_{2}=\mathrm{H}, \mathrm{R}_{3}=\mathrm{CH}_{3}$
(3) $\mathrm{R}_{1}=\mathrm{R}_{2}=\mathrm{Cl}, \mathrm{R}_{3}=\mathrm{H}$

Scheme 1: Complexes obtained according the reactions pathway.

TABLE 1: Analytical data for the complexes.

\begin{tabular}{|c|c|c|c|c|c|c|c|}
\hline Compound & No. & Color & $\mathrm{R}_{\mathrm{f}}^{\mathrm{a}}$ & Yield & & sis calc. (fou & \\
\hline & & & & $(\%)^{b}$ & $\mathrm{C}(\%)$ & $\mathrm{H}(\%)$ & $\mathrm{N}(\%)$ \\
\hline $\mathrm{Ru}(\mathrm{III}) \mathrm{ClL}^{1}$ & 1 & Green & 0.69 & 42 & $40.25(40.56)$ & $2.90(3.09)$ & $5.87(6.09)$ \\
\hline $\mathrm{Ru}(\mathrm{III}) \mathrm{ClL}^{2}$ & 2 & Green & 0.70 & 40 & $42.77(43.10)$ & $3.56(3.85)$ & $5.54(5.83)$ \\
\hline $\mathrm{Ru}(\mathrm{III}) \mathrm{ClL}^{3}$ & 3 & Green & 0.78 & 45 & $31.22(31.48)$ & $1.62(1.78)$ & 4.55 (4.79) \\
\hline
\end{tabular}

${ }^{\mathrm{a}}$ Retarding factor; noted $\mathrm{R}_{\mathrm{f}}$ (TLC), ${ }^{\mathrm{b}}$ based on mol number of starting material diaminoethane

TABLE 2: Spectroscopic data FT-IR and UV-Visible of the complexes.

\begin{tabular}{|c|c|c|c|c|c|c|c|c|c|}
\hline \multirow[b]{2}{*}{ Compound } & \multicolumn{4}{|c|}{ Infrared $\left(\mathrm{cm}^{-1}\right)$} & \multicolumn{5}{|c|}{$\mathrm{UV}$-vis $\lambda(\mathrm{nm})[\varepsilon]\left(\mathrm{M} \cdot \mathrm{cm}^{-1}\right)$} \\
\hline & $\begin{array}{c}v \\
(\mathrm{O}-\mathrm{H})\end{array}$ & $\begin{array}{c}\nu \\
(\mathrm{C}=\mathrm{N})\end{array}$ & $\begin{array}{c}v \\
(\mathrm{C}-\mathrm{O})\end{array}$ & & & & & & \\
\hline $\mathrm{H}_{2} \mathrm{~L}^{1}$ & 3090 & 1630 & 1293 & 252 & [3714] & & & 316 & {$[1856]$} \\
\hline $\mathrm{Ru}(\mathrm{III}) \mathrm{ClL}^{1}$ & & 1610 & 1313 & 257 & {$[916]$} & 280 & {$[500]$} & 407 & [250] \\
\hline $\mathrm{H}_{2} \mathrm{~L}^{2}$ & 3196 & 1623 & 1277 & 300 & {$[1072]$} & 350 & {$[600]$} & 398 & {$[473]$} \\
\hline $\mathrm{Ru}(\mathrm{III}) \mathrm{ClL}^{2}$ & & 1605 & 1345 & 300 & {$[650]$} & 388 & [327] & 467 & {$[218]$} \\
\hline $\mathrm{H}_{2} \mathrm{~L}^{3}$ & 3380 & 1665 & 1274 & 254 & {$[931]$} & 325 & [343] & 382 & {$[218]$} \\
\hline $\mathrm{Ru}(\mathrm{III}) \mathrm{ClL}^{3}$ & & 1601 & 1274 & 250 & [1249] & 325 & [315] & 425 & [500] \\
\hline
\end{tabular}

All compounds were obtained with the ligand dianion corresponding to the deprotonation of the two phenolic groups. Thus, these complexes of ruthenium appear to be cationic species with chloride anion as counter ion. So, the complexes formulae are supported by the elemental analysis, the spectroscopic data as IR, UV-Vis, and their electrochemical characteristics.
3.2. Infrared Spectra. The main vibration bands observed in the infrared spectra of the ligands and their ruthenium complexes are those of phenol, azomethine, and phenoxy groups (Table 2). For the ligands, a vibration band appearing as a broad one in the $3300-3400 \mathrm{~cm}^{-1}$ range indicates the presence of hydroxyl groups with hydrogen bonds. This band disappears in the cases of the corresponding complexes, 
suggesting the coordination of the metal ion through the $\mathrm{O}$ phenolic atoms. The stretching vibration bands of the azomethine group is shifted to lower wavenumbers, indicating that the nitrogen atoms are involved in the coordination [14-16, 50-53] leading to OONN tetradentate ligands. On the opposite side, a shift to higher values of the $\nu(\mathrm{C}-\mathrm{O})$ vibration bands of phenoxy groups was observed, corresponding to the simultaneous strengthening of the electronic density of these bonds and coordination of the oxygen atoms to the metallic center. These results are in good agreement with those reported for similar structures $[54,55]$.

3.3. Electronic Spectra. The electronic spectrum of the unsubstituted $\mathrm{H}_{2}$ Salen, in DMSO, showed two absorption bands at 252 and $316 \mathrm{~nm}$ while those of the both remaining ligands $\mathrm{H}_{2} \mathrm{~L}^{2}$ and $\mathrm{H}_{2} \mathrm{~L}^{3}$ exhibit three absorption bands between 254 and $398 \mathrm{~nm}$ (Table 2). These bands were attributed to the $\pi-\pi^{*}$ and $n-\pi^{*}$ transitions. These free ligands show other absorption bands assigned to the $\mathrm{n}$ $\pi^{*}$ and $n-\sigma^{*}$ transitions, respectively $[56,57]$. The electronic spectra of the ruthenium(III) complexes showed new absorption bands due to the coordination of the ruthenium ion. This coordination is accompanied by an hypsochromic effect showing that the bands appearing in the 407-467 nm region, assigned to the $\mathrm{d}-\pi^{*}$ charge transfer transitions, are overlapping with $\pi-\pi^{*}$ or $n-\pi^{*}$ transitions of the free ligands. These modifications in positions and intensities of the absorption bands confirm the coordination mode. As well, the molar extinction coefficients maxima $\varepsilon_{\max }$ is higher only for the tetrachlorinated complex $\mathbf{3}$ due to the huge electronic delocalisation caused by the presence of the metallic center bridging the two phenolic moieties comforted by the chlorine atoms as mentioned in the literature [56-59].

\section{Electrochemical Study}

In this study, we have, firstly, recorded the voltammograms of the complexes $\mathbf{1}, \mathbf{2}$, and $\mathbf{3}$ under nitrogen atmosphere using two axial bases 1- and 2-methylimidazole. Secondly, the same cyclic voltammetry studies were carried out under oxygen atmosphere.

4.1. Under Nitrogen Atmosphere. The cyclic voltammetry experiments were performed as described using acetonitrile solutions $\left(10^{-3} \mathrm{~mol} \cdot \mathrm{L}^{-1}\right)$ and $10^{-1} \mathrm{~mol} \cdot \mathrm{L}^{-1} \mathrm{TBAP}, 1-$ or 2 methylimidazole (1-Me-im or 2 -Me-im $\left.10^{-2} \mathrm{~mol} \cdot \mathrm{L}^{-1}\right)$. In this case, the voltammograms were recorded under nitrogen atmosphere at various sweep rates.

4.1.1. Complexes. The carbon atoms in our three ruthenium (III)-complexes were numbered according to the structure illustrated by Scheme 2.

The voltamperograms of the complexes 1,2 , and 3 were recorded in the -1000 to $+100 \mathrm{mV}$ range. Each of them shows a redox system at the cathodic potentials appearing before $-0.75 \mathrm{~V}$ corresponding to the redox system of molecular oxygen [60]. In this case, we have only studied

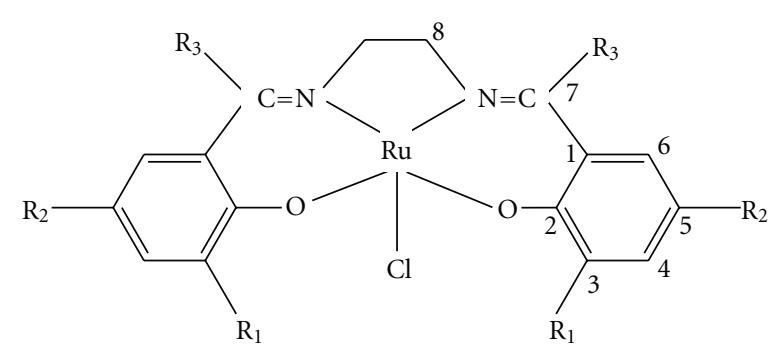

Scheme 2: Numbering of carbon atoms of Ru(III)-complex.

the $\mathrm{Ru}(\mathrm{III}) / \mathrm{Ru}(\mathrm{II})$ redox system according to the following equation:

$$
\mathrm{L}^{n} \mathrm{Ru}(\mathrm{III})+1 \mathrm{e}^{-} \rightleftharpoons \mathrm{L}^{n} \mathrm{Ru}(\mathrm{II})
$$

Where $\mathrm{L}^{n}: \mathrm{L}^{1}, \mathrm{~L}^{2}$, and $\mathrm{L}^{3}$. E and $\mathrm{C}$ are respectively electrochemical and chemical steps.

The electrochemical characteristics of these complexes such as $E_{1 / 2}$ values are $-0.622(\mathbf{1}),-0.565$ (2), and $-0.507 \mathrm{~V} / \mathrm{SCE}(3)$ These half-wave potentials $\left(E_{1 / 2}=\left(E_{\mathrm{pa}}-\right.\right.$ $\left.E_{\mathrm{pc}}\right) / 2$ ), involve $E_{\mathrm{pa}}$ and $E_{\mathrm{pc}}$ as potential values of oxidation and reduction waves of a redox couple. These $E_{1 / 2}$ values show an obvious shifting to the anodic potentials, caused by the substituents of the $\mathrm{H}_{2}$ Salen. Thus, the complex 2 is dimethylated at $\left(\mathrm{C}_{7}, \mathrm{C}_{7^{\prime}}\right)$ positions while the third one 3 is rather tetrachlorinated at $\left(\mathrm{C}_{3}, \mathrm{C}_{3^{\prime}}\right)$ and $\left(\mathrm{C}_{5}, \mathrm{C}_{5^{\prime}}\right)$ positions. So, its complex 3, exhibits a withdrawing electronic effect, inducing an $E_{1 / 2}=-0.507 \mathrm{~V}$ which is significantly shifted to more anodic potentials as usually expected. The corresponding $\Delta E_{\mathrm{p}}=\left(E_{\mathrm{pa}}-E_{\mathrm{pc}}\right)$ values are stable around $65-75 \mathrm{mV}$ for all three complexes. Their $I_{p a} / I_{p c}$ ratios increase with increasing sweep rate, converging to 1 , suggesting quasireversible redox systems $[61,62]$ (Table 3 ). These results are consistent with the electronic effects due to the substituents such as methyl and chlorine grafted on the $\mathrm{H}_{2}$ Salen [22-25, 47].

4.1.2. Complexes with 1- or 2-Methylimidazole. The addition of an amount of $10^{-2} \mathrm{M}$ of a nitrogen base like 1- or 2-Me-im., acting as an axial ligand bound to the metal center $10^{-3} \mathrm{M}$, leads to a well-defined redox system without any significant shift of $E_{1 / 2}$ values. An enhancement of the current peaks $I_{\mathrm{pa}}$ and $I_{\mathrm{pc}}$ is observed as previously mentioned for iron [63] or manganese complexes [22-25].

\subsection{Under Oxygen Atmosphere}

4.2.1. Complexes without Axial Base. In this case, the reduction wave of the $\mathrm{Ru}(\mathrm{III}) / \mathrm{Ru}$ (II) redox couple appears as two successive waves $E_{\mathrm{pc} 1}$ and $E_{\mathrm{pc} 2}$ indicating the electroreduction of two species. This may be explained by the following equations:

$$
\begin{aligned}
& \mathrm{L}^{n} \mathrm{Ru}(\mathrm{II})+\mathrm{O}_{2} \rightleftharpoons \mathrm{L}^{n} \mathrm{Ru}(\mathrm{III})-\mathrm{O}-\mathrm{O}^{\bullet} \\
& \mathrm{L}^{n} \mathrm{Ru}(\mathrm{III})-\mathrm{O}-\mathrm{O}^{\bullet}+1 \mathrm{e}^{-} \longrightarrow \mathrm{L}^{n} \mathrm{Ru}(\mathrm{III})-\mathrm{O}-\mathrm{O}^{-} \\
& \mathrm{L}^{n} \mathrm{Ru}(\mathrm{III})+\mathrm{O}_{2} \rightleftharpoons \mathrm{L}^{n} \mathrm{Ru}(\mathrm{IV})-\mathrm{O}-\mathrm{O}^{\bullet} \\
& \mathrm{L}^{n} \mathrm{Ru}(\mathrm{IV})-\mathrm{O}-\mathrm{O}^{\bullet}+2 \mathrm{e}^{-} \longrightarrow \mathrm{L}^{n} \mathrm{Ru}(\mathrm{III})-\mathrm{O}-\mathrm{O}^{-}
\end{aligned}
$$


TABLE 3: Cyclic voltammetry data of the $\mathrm{Ru}(\mathrm{III})$-complexes under nitrogen and oxygen atmosphere.

\begin{tabular}{lcccccccc}
\hline \multicolumn{8}{c}{ Electrochemical characteristics of the Ru(III)-complexes } \\
\hline Complex & \multicolumn{7}{c}{ Under oxygen } \\
& $E_{\mathrm{pc}}(\mathrm{V})$ & $E_{\mathrm{pa}}(\mathrm{V})$ & $E_{1 / 2}(\mathrm{~V})^{\mathrm{a}}$ & $I_{\mathrm{pa} /} I_{\mathrm{pc}}$ & $E_{\mathrm{pc} 1}(\mathrm{~V})$ & $E_{\mathrm{pc} 2}(\mathrm{~V})$ & $I_{\mathrm{pc}}(\mu \mathrm{A})^{\mathrm{b}}$ & $I_{\mathrm{pc}}\left(\mathrm{O}_{2}\right) / I_{\mathrm{pc}}\left(\mathrm{N}_{2}\right)$ \\
\hline $\mathbf{1}$ & 0.660 & 0.585 & 0.622 & 0.80 & 0.580 & 0.720 & 09.60 & 1.60 \\
$\mathbf{2}$ & 0.600 & 0.530 & 0.565 & 0.80 & 0.520 & 0.700 & 14.40 & 2.57 \\
$\mathbf{3}$ & 0.540 & 0.475 & 0.507 & 0.86 & 0.500 & 0.620 & 14.80 & 1.76 \\
\hline
\end{tabular}

${ }^{\mathrm{a}} E_{1 / 2}=\left(E_{\mathrm{pa}}-E_{\mathrm{pc}}\right) / 2$; values obtained under nitrogen.

${ }^{\mathrm{b}} I_{\mathrm{pc}}=\left(I_{\mathrm{pc} 1}+I_{\mathrm{pc} 2}\right)$; values between brackets are obtained under oxygen.

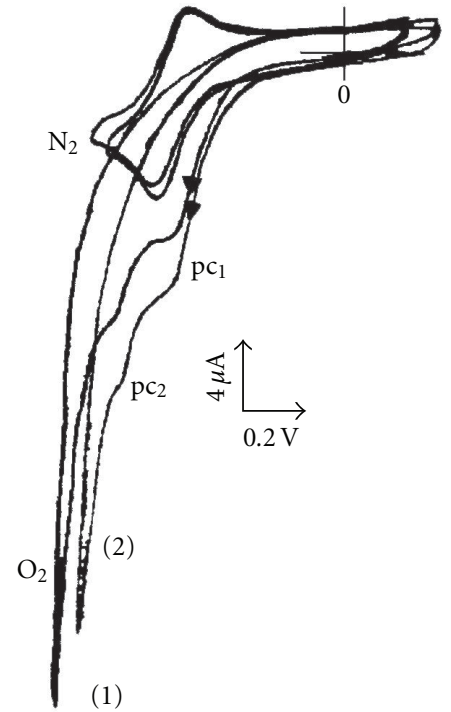

FIGURE 1: Voltammograms of complex $3 ; 10^{-3} \mathrm{M}$ in $\mathrm{CH}_{3} \mathrm{CN}$ with TBAP $10^{-1} \mathrm{M}$ obtained at scan rate $25 \mathrm{mV} \mathrm{s}^{-1}$. (1) Under nitrogen without 1-methylimidazole and then with oxygen; (2) under nitrogen in presence of 1-methylimidazole and then with oxygen.

The chemical steps involving the reversible reactions with oxygen are (2) and (4) whereas the electrochemical ones such as the reduction waves $E_{\mathrm{pc} 1}$ and $E_{\mathrm{pc} 2}$ may result from electroreduction of two different species as represented by (3) for $E_{\mathrm{pc} 1}$ (Figure 5, way (a)) and (5) for $E_{\mathrm{pc} 2}$ (Figure 5, way (b)). The second one $E_{\mathrm{pc} 2}$, appearing at more cathodic potentials, was assigned to the bielectronic transfer on the metallic center of $\mathrm{L}^{n} \mathrm{Ru}(\mathrm{IV})-\mathrm{O}-\mathrm{O}^{\bullet}$ (5) giving the $\mathrm{L}^{n} \mathrm{Ru}(\mathrm{III})-$ $\mathrm{O}-\mathrm{O}^{-}$species, which are simultaneously produced by $(3)$ according a monoelectronic transfer.

When the $\mathrm{L}^{n} \mathrm{Ru}(\mathrm{II})$ species are coordinated to 2methylimidazole, they exhibit a greater reactivity towards oxygen causing the disappearance of $E_{\mathrm{pc} 2}$ to the benefit of $E_{\mathrm{pcl}}$ as illustrated by Figure 3 .

However, for this reason, it is worth noting that such $\mathrm{M}^{\mathrm{II}}$-oxygenated species are often usually reduced at the same potential of their formation [18, 21-25, 63] leading to the superoxo moeties. Similarly, the oxygenated $\mathrm{Ru}(\mathrm{IV})-$ $\mathrm{O}_{-} \mathrm{O}^{-}$species, resulting from (4), are also reduced at the same potential value, giving the same result $\mathrm{L}^{n} \mathrm{Ru}(\mathrm{III})-\mathrm{O}_{-} \mathrm{O}^{-}$ obtained from (5) (Figure 1). The peak-to-peak separation potentials $\left(\Delta E_{\mathrm{p}}\right)$ between these two reduction waves $\left(E_{\mathrm{pcl}}\right.$, $\left.E_{\mathrm{pc} 2}\right)$ were estimated to be about $100 \mathrm{mV}$. Therefore, this behaviour shows a particular reactivity for the $\mathrm{Ru}(\mathrm{III})$ complexes when they are compared to their analogous such as $\mathrm{Mn}$ (III)-, $\mathrm{Fe}(\mathrm{III})-$, and $\mathrm{Co}(\mathrm{III})$-complexes. So, this excess of reactivity involving an easy reaction of the $\mathrm{Ru}(\mathrm{III})$ species with molecular oxygen was not observed seeing that, to our knowledge, only the divalent form $\mathrm{M}$ (II) of these complexes is known as the more reactive species towards the oxygen.

In this case, the redox systems of all these complexes appear always before those of oxygen but their $E_{1 / 2}$ values are very slightly shifted to the more cathodic potentials by about $33-55 \mathrm{mV}$. For example, the nearer $E_{1 / 2}$ value is that of the complex 1 which is observed at -0.660 instead of $-0.622 \mathrm{~V}$ under nitrogen atmosphere. So, under the same experimental conditions and under oxygen atmosphere, the superoxide species are exclusively produced as reported by Sawyer et al. [60]. For this reason, all the complexes 1, 2, and 3 (Table 1: $E_{1 / 2}<-750 \mathrm{mV}$ ) may be considered as catalysts activating the molecular oxygen like P450 cytochrome [18]. The shape of the voltammograms obtained from these $\mathrm{Ru}(\mathrm{III})$-complexes is represented in Figure 1.

On these voltammograms, it was observed that the halfwave potential values remain stable under nitrogen or oxygen atmosphere noting that the electroreduction of the metalsuperoxo species occurred at the same potential of their formation as it was already indicated. When varying the scan rate, the cathodic peak currents $\left(I_{\mathrm{pc}}\right)$ decrease at low sweep rates leading to the lower $I_{\mathrm{pc}}\left(\mathrm{O}_{2}\right) / I_{\mathrm{pc}}\left(\mathrm{N}_{2}\right)$ ratios $1.60(1), 2.57$ (2) and $1.76(3)$ at $10 \mathrm{mV} \mathrm{s}^{-1}$ while, at scan rates moderately higher $\left(100 \mathrm{mV} \mathrm{s}^{-1}\right)$, they are $3.06,3.27$, and 3.48 , respectively. Considering the reversibility of oxygenation reaction for these species, this behavior may be approached to their corresponding manganese(III)-superoxo species [22-25].

4.2.2. Complexes with 1-Methylimidazole. First, under nitrogen atmosphere, the addition of $10^{-2} \mathrm{M}$ of nitrogen base like 1-Me-im., acting as an axial ligand, leads to a welldefined redox system without any significant displacement of $E_{1 / 2}$ values. There is, also, a neat enhancement of the peak currents $I_{\mathrm{pa}}$ and $I_{\mathrm{pc}}$ after the addition of a nitrogen base as 1-methylimidazole [63]. This nitrogen base coordinated to the central metal ion enhances the coordination number and produces an improvement of the electrophilic character on the metal center, and its further reaction with molecular oxygen becomes easier.

Under oxygen atmosphere, the shape of the voltammograms is quite similar to those obtained without 1-methylimidazole except some differences in their wave intensities 
exhibiting a relative high reactivity of the ruthenium(III)complexes towards oxygen molecules as illustrated in Figures 1 and 3. Thus, the $E_{\mathrm{pcl}}$ wave enhancement (3) was noted when comparing these voltammograms with those recorded in the same experimental conditions without nitrogen base. This enhancement involving the reaction of the $\mathrm{Ru}(\mathrm{II})$ species with oxygen (3) was estimated to be $10-13 \%$ according to the nature of the complex. This behavior is also accompanied by the diminishing of the $E_{\mathrm{pc} 2}$ wave up to $28-37 \%$ suggesting an accelerating of the chemical reaction between $\mathrm{Ru}$ (II) species and oxygen (Figure 5, way (a)) when their coordination number is increased by an addition of an amount of 1-methylimidazole (10 equivalents).

The electrocatalytic currents of these three complexes were represented by the ratio $I_{\mathrm{pc}} \mathrm{O}_{2} / I_{\mathrm{pc}} \mathrm{N}_{2}$ values and are 1.75 (1), 2.42 (2), and 1.90 (3). It should be noted that these ratios were calculated by summing the $I_{\mathrm{pc}}$ cathodic current $\left(I_{\mathrm{pcl}}+\right.$ $I_{\mathrm{pc} 2}$ ) values obtained in the presence of 1-methylimidazole under oxygen atmosphere. The greater ratios are mainly obtained from an excess of redox properties induced by the $\sigma$ donor effect of substituents on the metal centre such as those of the two methyl groups, symmetrically grafted on the complex (2) Ru(III)-[7,7'-(Me) ${ }_{2}$ Salen].

Under these experimental conditions (Figure 2) and Table 3, all the voltammograms of the complexes give almost similar results. Thus, the redox system of the metallic center $\mathrm{Ru}(\mathrm{II}) / \mathrm{Ru}$ (III) was studied and the electrochemical characteristics obtained as peak-to-peak separation potential $\Delta E_{\mathrm{p}}$ values, $I_{\mathrm{pc}} / f\left(v^{1 / 2}\right)$ and $I_{\mathrm{pa}} / I_{\mathrm{pc}}$ ratio are consistent with a quasireversible redox couple $[61,62]$.

4.2.3. Complexes with 2-Methylimidazole. The addition of $10^{-2} \mathrm{M}$ of 2-methylimidazole to the $\mathrm{Ru}(\mathrm{III})$ complex $10^{-3} \mathrm{M}$, acting as an axial ligand, induces the same effects as 1methylimidazole but with a higher speed of the chemical reaction (3) and the disappearance of $E_{\mathrm{pc} 2}$ reduction wave (5) to the benefit of $E_{\mathrm{pcl}}$ reduction wave (3) as shown in Figure 3.

This expresses the relative high reactivity of the ruthenium(II) complex molecules towards oxygen when 1methylimidazole is replaced with 2-methylimidazole. This result is observed with all our $\mathrm{Ru}(\mathrm{III})$-complexes. This relative reactivity induced by the use of 1- or 2-methylimidazole as apical bases indicates a higher electrophilic character on the metal center leading to a greater accelerating of the oxygen consumption by the $\mathrm{Ru}(\mathrm{II})$ species (2). To our knowledge, these results were not reported in the literature, seeing that these complexes were not studied by cyclic voltammetry in the presence of different nitrogen bases. In this case, when adding 1- or 2-Me-im., the speed of formation of the superoxo or peroxo species (peroxidase form) is significantly increased as expressed by the ratios $I_{\mathrm{pc}}\left(\mathrm{O}_{2}\right) / I_{\mathrm{pc}}\left(\mathrm{N}_{2}\right)$ in Table 4. Finally, it must be noted that these oxygenation reactions of ruthenium complexes are reversible when the solutions are bubbled in argon or nitrogen atmosphere, as reported in the literature [22-25, 63].

These results may be connected with the high relative basicity of 1- and 2-methylimidazole as previously reported in literature [17]. Moreover, we have also determined the number of electrons that are involved in these electrochem-

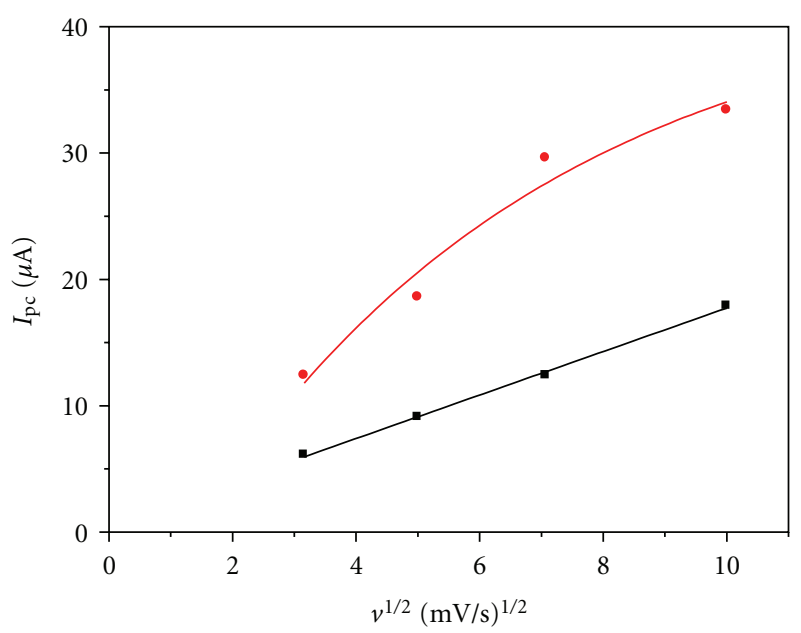

(a)

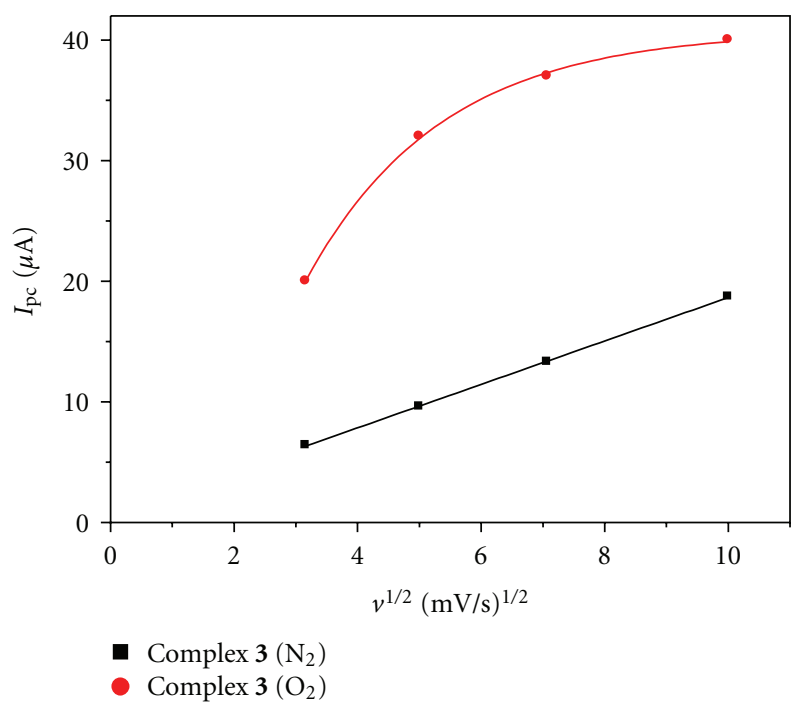

(b)

Figure 2: Curves $I_{\mathrm{pc}}=f\left(v^{1 / 2}\right)$ of complex $3 ; 10^{-3} \mathrm{M}$ in $\mathrm{CH}_{3} \mathrm{CN}$ solutions $10^{-1} \mathrm{M}$ TBAP. (a) 1-methylimidazole; (b) 2methylimidazole.

ical reactions. There are few reports in the literature on these reactions with molecular oxygen, reduced to hydrogen peroxide or water via a two- or four-electron transfer on chemically modified electrodes. The main papers were published by Horwitz et al. [21] and Taqui Khan et al. [47], Anson et al. [64-66], and Chang et al. [67-69]. Here, we have determined the number of electrons for our ruthenium complexes using coulometry after electrolysis under oxygen atmosphere.

4.3. Coulometry Study. For this study, we have proceeded as reported in the literature [47]. Thus, our three complexes were electrolyzed at controlled potentials in a threecompartment cell (acetonitrile solution) in presence of 1methylimidazole as an apical base. Before each experiment, a pre-electrolysis was achieved for at least one half hour under nitrogen atmosphere in order to eliminate any electroactive 
TABLE 4: Electrochemical characteristics of the $\mathrm{Ru}(\mathrm{III})$-complexes 1, 2, and 3 in presence of 1- and 2-methylimidazole under $\mathrm{N}_{2}$ then under $\mathrm{O}_{2}$ atmosphere.

\begin{tabular}{|c|c|c|c|c|c|c|}
\hline Complex & $E_{1 / 2}(\mathrm{mV})^{\mathrm{a}}$ & $\Delta E_{\mathrm{p}}(\mathrm{mV})$ & $I_{\mathrm{pcl}}(\mu \mathrm{A})$ & $I_{\mathrm{pc} 2}(\mu \mathrm{A})$ & $I_{\mathrm{pa}} / I_{\mathrm{pc}}$ & $I_{\mathrm{pc}}\left(\mathrm{O}_{2}\right) / I_{\mathrm{pc}}\left(\mathrm{N}_{2}\right)^{\mathrm{b}}$ \\
\hline \multicolumn{7}{|c|}{ Electrochemical characteristics of the $\mathrm{Ru}(\mathrm{III})$-complexes } \\
\hline \multicolumn{7}{|c|}{ With 1-methylimidazole } \\
\hline 1 & $580(622)$ & $70(70)$ & $6.4(10.0)$ & $-(1.2)$ & 0.75 & 1.75 \\
\hline 2 & $520(565)$ & $75(75)$ & $5.6(11.6)$ & $-(2.0)$ & 0.82 & 2.42 \\
\hline 3 & $500(507)$ & $65(65)$ & $8.8(14.8)$ & $-(2.0)$ & 0.86 & 1.90 \\
\hline \multicolumn{7}{|c|}{ With 2-methylimidazole } \\
\hline 1 & $580(622)$ & $70(70)$ & $6.6(16.6)$ & $-(0.0)$ & 0.80 & 2.51 \\
\hline 2 & $520(565)$ & $70(70)$ & $6.4(20.9)$ & $-(0.0)$ & 0.82 & 3.26 \\
\hline 3 & $500(507)$ & $75(75)$ & $9.6(32.5)$ & $-(0.0)$ & 0.88 & 2.45 \\
\hline
\end{tabular}

${ }^{\mathrm{a}} E_{1 / 2}$; values obtained under nitrogen.

${ }^{\mathrm{b}} I_{\mathrm{pc}}=\left(I_{\mathrm{pc} 1}+I_{\mathrm{pc} 2}\right)$; values given between brackets are obtained under oxygen.

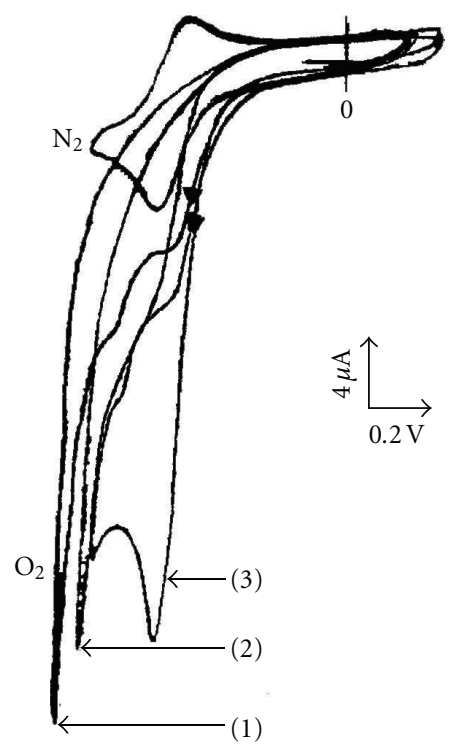

Figure 3: Voltammograms of complex $3 ; 10^{-3} \mathrm{M}$ in $\mathrm{CH}_{3} \mathrm{CN}$ with TBAP $10^{-1} \mathrm{M}$ obtained at scan rate $25 \mathrm{mV} \mathrm{s}^{-1}$ : (1) Under nitrogen and then oxygen; (2) in presence of 1-methylimidazole under oxygen; (3) in presence of 2-methylimidazole under oxygen atmosphere.

impurities. The number of electrons was finally calculated from the following Faraday equation:

$$
n=\frac{Q}{(m / M) \cdot F}
$$

where $n$ is the number of electrons involved in the reaction, and $Q$ the amount of electricity, $m$, and $M$ are, respectively, the mass of the complex and its molar mass. The results are given in Table 5.

These results suggest that the major part of the compound $(75 \%)$ was electroreduced according to the first reduction wave $E_{\mathrm{pcl}}$ and only $25 \%$ were electrolyzed following the second reduction wave $E_{\mathrm{pc} 2}$. When the 2-methylimidazole is used as an apical base, the complex is exclusively electrolyzed according to the first reduction wave $E_{\mathrm{pcl}}$
TABLE 5: Number of electrons involved in the electrolyses of $\mathrm{Ru}(\mathrm{III})$-complexes under oxygen atmosphere in presence of 1methylimidazole.

\begin{tabular}{lcc}
\hline \multicolumn{2}{c}{ Determination of number of electrons for waves $E_{\mathrm{pc} 1}$ and $E_{\mathrm{pc} 2}$} \\
\hline Complex & Number of electrons $E_{\mathrm{pc} 1}$ & Number of electrons $E_{\mathrm{pc} 2}$ \\
\hline $\mathbf{1}$ & 1.50 & 0.44 \\
$\mathbf{2}$ & 1.60 & 0.36 \\
$\mathbf{3}$ & 1.50 & 0.46 \\
\hline
\end{tabular}

with high reactivity of the $\mathrm{Ru}(\mathrm{II})$ species towards dioxygen molecules which were subsequently electroreduced by a monoelectronic transfer process (3). At this level, it seems us important to note this particular behavior, characterizing the high reactivity of $\mathrm{Ru}(\mathrm{III})$-Schiff base complexes when they are compared to their analogs such as the iron(III)[63] and $\mathrm{Mn}(\mathrm{III})$-complexes [22-25] with which the metaloxo $(\mathrm{M}=\mathrm{O})$ species are almost exclusively formed from the electroreduced $\mathrm{M}(\mathrm{II})$-species.

4.4. Complexes with 1- or 2-Methylimidazole and Benzoic Anhydride. Benzoic anhydride reacts with superoxo intermediates, giving an oxo compound with elimination of one oxygen atom according to the following equation $[6,21,36$, 47]:

$$
\begin{gathered}
\mathrm{L}^{n} \mathrm{Ru}(\mathrm{III})-\mathrm{O}-\mathrm{O} \bullet+1 \mathrm{e}^{-}+\left(\mathrm{C}_{6} \mathrm{H}_{5} \mathrm{CO}\right)_{2} \mathrm{O} \\
\rightleftharpoons \mathrm{L}^{n} \mathrm{Ru}^{\mathrm{V}}=\mathrm{O}+2 \mathrm{C}_{6} \mathrm{H}_{5} \mathrm{CO}_{2}{ }^{-} \\
\mathrm{L}^{n} \mathrm{Ru}(\mathrm{IV})-\mathrm{O}-\mathrm{O} \bullet+2 \mathrm{e}^{-}+\left(\mathrm{C}_{6} \mathrm{H}_{5} \mathrm{CO}\right)_{2} \mathrm{O} \\
\rightleftharpoons \mathrm{L}^{n} \mathrm{Ru}^{\mathrm{V}}=\mathrm{O}+2 \mathrm{C}_{6} \mathrm{H}_{5} \mathrm{CO}_{2}{ }^{-}
\end{gathered}
$$

When benzoic anhydride is added to the acetonitrile solution of a complex and Me-im, we note a significant enhancement of the cathodic peak current $I_{\mathrm{pc}}$. In the mean time, the anodic peak current is clearly diminishing, showing a loss of reversibility of the $\mathrm{Ru}(\mathrm{III}) / \mathrm{Ru}(\mathrm{II})$ redox system. This is due to an important consumption of the two superoxo species ( $\mathrm{L}^{n} \mathrm{Ru}(\mathrm{III})-\mathrm{O}-\mathrm{O}^{\bullet}+1 \mathrm{e}^{-}$and $\left.\mathrm{L}^{n} \mathrm{Ru}(\mathrm{IV})-\mathrm{O}-\mathrm{O}^{\bullet}+2 \mathrm{e}^{-}\right)$ 
TABLE 6: Electrochemical characteristics giving the electrocatalytic currents $I_{\mathrm{pc}}\left(\mathrm{O}_{2}\right) / I_{\mathrm{pc}}\left(\mathrm{N}_{2}\right)$.

\begin{tabular}{|c|c|c|c|c|c|}
\hline Complex & $v\left(\mathrm{mV} \mathrm{s}^{-1}\right)$ & $-E_{\mathrm{pcl}}(\mathrm{mV} / \mathrm{SCE})$ & $I_{\mathrm{pc}}\left(\mathrm{O}_{2}\right)(\mu \mathrm{A})$ & $I_{\mathrm{pc}}\left(\mathrm{N}_{2}\right)(\mu \mathrm{A})$ & $I_{\mathrm{pc}}\left(\mathrm{O}_{2}\right) / I_{\mathrm{pc}}\left(\mathrm{N}_{2}\right)$ \\
\hline \multicolumn{6}{|c|}{ Electrochemical characteristics of the $\mathrm{Ru}(\mathrm{III})$-complexes } \\
\hline \multicolumn{6}{|c|}{ With 1-methylimidazole } \\
\hline \multirow{2}{*}{2} & 10 & 680 & $080.00^{\mathrm{a}}$ & 03.50 & 22.85 \\
\hline & 100 & 710 & $086.00^{\mathrm{a}}$ & 12.00 & 07.16 \\
\hline \multirow{3}{*}{3} & 10 & 600 & $060.00^{\mathrm{a}}$ & 06.00 & 10.00 \\
\hline & 100 & 660 & $067.00^{\mathrm{a}}$ & 16.00 & 04.20 \\
\hline & \multicolumn{5}{|c|}{ With 2-methylimidazole } \\
\hline \multirow{2}{*}{2} & 10 & 680 & 140.00 & 03.80 & 36.84 \\
\hline & 100 & 710 & 136.00 & 12.80 & 10.62 \\
\hline \multirow{2}{*}{3} & 10 & 600 & 075.00 & 06.40 & 11.72 \\
\hline & 100 & 660 & 073.00 & 18.70 & 04.00 \\
\hline
\end{tabular}

${ }^{\mathrm{a}} I_{\mathrm{pc}}=\left(I_{\mathrm{pc} 1}+I_{\mathrm{pc} 2}\right)$.

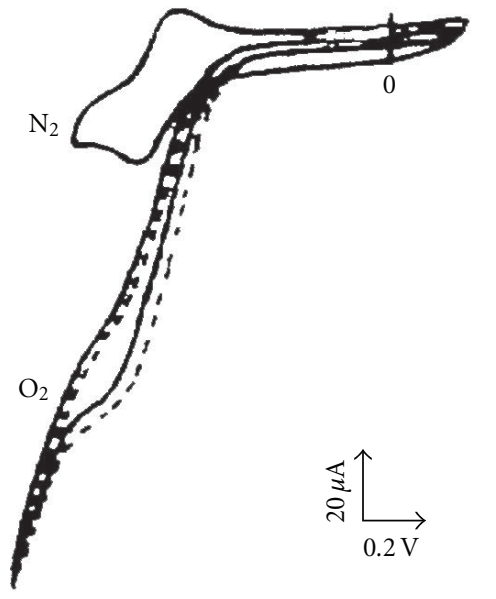

(a)

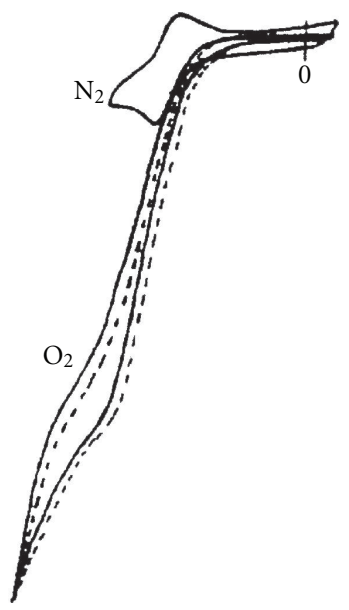

(b)

FIGURE 4: Voltammograms of complex $2 ; 10^{-3} \mathrm{M}$ in $\mathrm{CH}_{3} \mathrm{CN}$ with TBAP $10^{-1} \mathrm{M}$ obtained in presence of nitrogen base $10^{-2} \mathrm{M}$ and benzoic anhydride $10^{-1} \mathrm{M}$ under nitrogen and then oxygen atmosphere at scan rate $25 \mathrm{mV} \mathrm{s}^{-1}$. (a) 1-methylimidazole; (b) 2methylimidazole, (full line: with pure benzoic anhydride; dotted line: with benzoic anhydride containing $2-3 \%$ of its acid).

according to (7) and (8) where they are transformed to the corresponding metal-oxo species. As soon as these superoxo species are produced, the electrophilic intermediates (i.e., $\mathrm{C}_{6} \mathrm{H}_{5}-\mathrm{CO}^{+}$) react faster to produce the metal-oxo species $[6,21,47]$. Of course, an important enhancement of the two cathodic peak currents $I_{\mathrm{pc}}\left(\mathrm{O}_{2}\right)$ was observed at each one of the both reduction waves $E_{\mathrm{pc} 1}$ and $E_{\mathrm{pc} 2}$ as previously indicated. These two waves explain the formation of the ruthenium-oxo species, which could be further involved in the epoxidation of olefins or oxidation of hydrocarbons (Figure 4).

These ruthenium-oxo species are formed at the same potential values than the corresponding superoxo species $\left(E_{\mathrm{pcl}}\right.$ and $\left.E_{\mathrm{pc} 2}\right)$. At this important step, the ruthenium-oxo species could transfer their oxygen atom to the substrate leading to an efficient electrocatalytic cycle or they are simply electrochemically reduced to recover their initial form of the ruthenium(III)-complex giving an inefficient electrocatalytic cycle as illustrated in Figure 5 [21-25].

The enhancement of the cathodic peak current $I_{\mathrm{pc}}\left(\mathrm{O}_{2}\right)$ expresses a catalytic activity towards oxygen as given by the $I_{\mathrm{pc}}\left(\mathrm{O}_{2}\right) / I_{\mathrm{pc}}\left(\mathrm{N}_{2}\right)$ ratio. Figure 4 showed clearly that the $I_{\mathrm{pc}}\left(\mathrm{O}_{2}\right)$ is not influenced by the traces of benzoic acid as observed for their corresponding Manganese(III)complexes where the electrocatalytic efficiency was seriously affected [22-25]. The $I_{\mathrm{pc}}$ values plotted versus the square root of sweep rates (Figure 6) shows also higher ratios of $I_{\mathrm{pc}}\left(\mathrm{O}_{2}\right) / I_{\mathrm{pc}}\left(\mathrm{N}_{2}\right)$ at lower scan rates, suggesting more time to achieve the chemical reaction with oxygen as illustrated in Figure 6.

Their shapes are typical of a high electrocatalytic activity towards the reaction with oxygen, to produce the metaloxo derivatives which might transfer their oxygen atom to a substrate in the oxidation reactions of hydrocarbons. Thus, as it can be observed in Table 6, showing systematically higher values for the $I_{\mathrm{pc}}\left(\mathrm{O}_{2}\right) / I_{\mathrm{pc}}\left(\mathrm{N}_{2}\right)$ ratios, mainly with 2MeIm. or 1-Me-im. $\left(10^{-2} \mathrm{M}\right)$ in the presence of benzoic anhydride $\left(10^{-1} \mathrm{M}\right)$ as activator, expressing the formation of ruthenium-oxo species from the superoxo ones.

Under these experimental conditions and with 1MeIm. or 2-MeIm., the cathodic peak current ratios $I_{\mathrm{pc}}\left(\mathrm{O}_{2}\right) / I_{\mathrm{pc}}\left(\mathrm{N}_{2}\right)$ are remarkably increased particularly at lower scan rates $\left(10 \mathrm{mV} \mathrm{s}^{-1}\right)$. This improvement at lower scan rates $\left(10 \mathrm{mV} \mathrm{s}^{-1}\right)$ implies a sufficient time to achieve the chemical reaction between ruthenium species and oxygen. These results allow to conclude that the best electrocatalytic currents are obtained, as well, at lower scan rates $\left(10 \mathrm{mV} \mathrm{s}^{-1}\right)$ 22.85 (1-MeIm.) and 36.84 (2-MeIm.) for the complex (2). These current ratios $I_{\mathrm{pc}}\left(\mathrm{O}_{2}\right) / I_{\mathrm{pc}}\left(\mathrm{N}_{2}\right)$ are fairly higher without any comparison to those obtained with their analogous of manganese, iron, and cobalt already mentioned. Regarding the complex 3, it shows current ratios $I_{\mathrm{pc}}\left(\mathrm{O}_{2}\right) / I_{\mathrm{pc}}\left(\mathrm{N}_{2}\right)$ relatively lower, but they should be more efficient towards olefins epoxidation for their robustness, acquired by the chlorine atoms grafted on the ligand as yet reported in the 


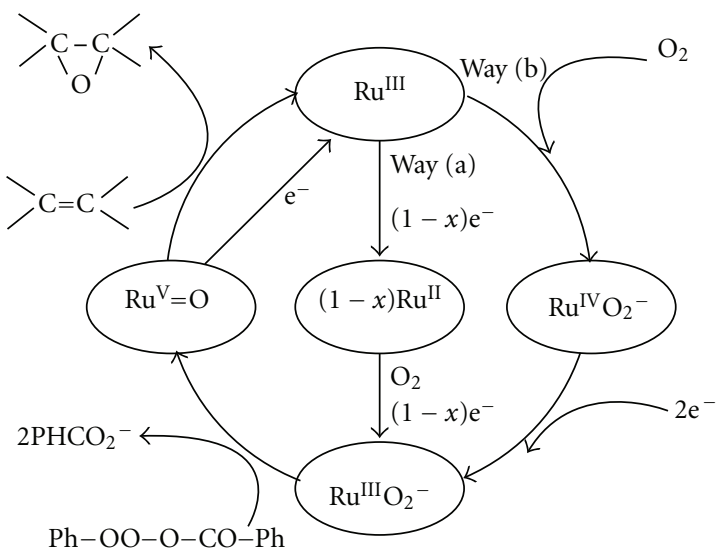

Figure 5: Proposed scheme for the electrocatalytic epoxidation of olefins or oxidation of hydrocarbons.

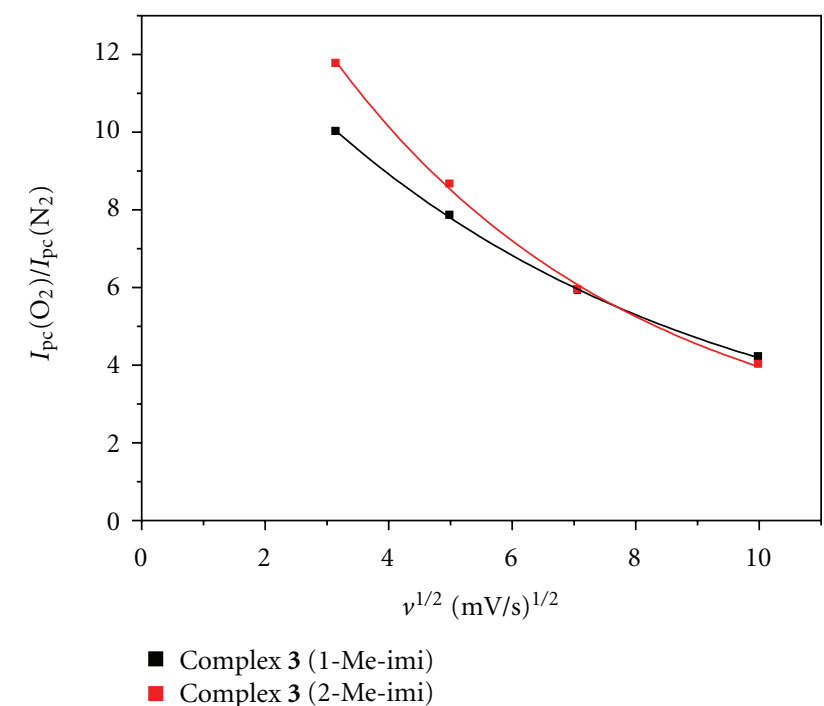

Figure 6: $I_{\mathrm{pc}}\left(\mathrm{O}_{2}\right) / I_{\mathrm{pc}}\left(\mathrm{N}_{2}\right)=f\left(v^{1 / 2}\right)$ Curves for complex 3; $\left(10^{-3} \mathrm{M}\right.$, acetonitrile). (a) 1-methylimidazole, (b) 2-methylimidazole.

literature for the polyhalogenated Schiff base $[22-25,63]$ or porphyrinic complexes [70, 71]. Thus, the $\mathrm{Ru}(\mathrm{III})$ and $\mathrm{Ru}(\mathrm{II})$ species may develop an important and particular reactivity towards molecular oxygen as in the diverse systems of P450 cytochrome [72].

\section{Conclusion}

In this work, we have showed that the $\mathrm{Ru}(\mathrm{III})$-species develop a particular reactivity towards molecular oxygen in comparison to their corresponding analogs species of manganese(III), iron(III), and cobalt(III). These latter complexes exhibit a reactivity quite similar towards oxygen when they are in their divalent form M(II). In this case, it was also revealed that the formation of byproducts such as $\mu$-oxodimers are advantageously avoided with the $\mathrm{Ru}(\mathrm{III})$ complexes. In the presence of benzoic anhydride, the electrocatalytic currents $I_{\mathrm{pc}}\left(\mathrm{O}_{2}\right) / I_{\mathrm{pc}}\left(\mathrm{N}_{2}\right)$ are remarkably exalted particularly when 2-methylimidazole is used and they are seven times greater than their $\mathrm{Mn}(\mathrm{III}) \mathrm{Cl}-\mathrm{Salen}$ analogs. Therefore, these $\mathrm{Ru}(\mathrm{III})$-complexes can work as good catalysts in biomimetic oxidation or as oxygen sensors operating with high sensitivity.

\section{References}

[1] H. S. Schiff, "Sur quelques dérivés phéniques des aldéhydes," Ann. Chim. (Paris), vol. 131, p. 118, 1864.

[2] L. Canali and D. C. Sherrington, "Utilisation of homogeneous and supported chiral metal(salen) complexes in asymmetric catalysis," Chemical Society Reviews, vol. 28, no. 2, pp. 85-93, 1999.

[3] E. N. Jacobsen, "Asymmetric catalysis of epoxide ring-opening reactions," Accounts of Chemical Research, vol. 33, no. 6, pp. 421-431, 2000.

[4] T. Katsuki, "Catalytic asymmetric oxidations using optically active (salen) manganese (III) complexes as catalysts," Coordination Chemistry Reviews, vol. 140, pp. 189-214, 1995.

[5] D. A. Atwood and M. J. Harvey, "Group 13 compounds incorporating Salen ligands," Chemical Reviews, vol. 101, no. 1, pp. 37-52, 2001.

[6] M. M. T. Khan, S. H. Mehta, A. P. Rao, and K. N. Bhatt, "Electrocatalytic oxidation of organic substrates with oxygen using ruthenium-Schiff base complex," Journal of Molecular Catalysis, vol. 75, no. 3, pp. 245-251, 1992.

[7] WA. H. Leung and C. M. Che, "Oxidation chemistry of ruthenium-salen complexes," Inorganic Chemistry, vol. 28, no. 26, pp. 4619-4622, 1989.

[8] S. E. Creager, S. A. Raybuck, and R. W. Murray, "An efficient electrocatalytic model cytochrome P-450 epoxidation cycle," Journal of the American Chemical Society, vol. 108, no. 14, pp. 4225-4227, 1986.

[9] A. A. Isse, A. Gennaro, E. Vianello, and C. Floriani, "Electrochemical reduction of carbon dioxide catalyzed by $\left[\mathrm{Co}^{I}\right.$ (salophen)Li] " Journal of Molecular Catalysis, vol. 70, no. 2, pp. 197-208, 1991.

[10] S. F. Tan, P. H. Leung, and W. C. Sin, "Catalytic autooxidation of p-anisaldehyde and styrene by a cobalt bis-schiff base complex," Transition Metal Chemistry, vol. 16, no. 5, pp. 542$545,1991$.

[11] J. P. Collman, T. R. Halbert, K. S. Suslick, and T. Spiro, Eds., Metal Ion Activation of Dioxygen, Wiley Interscience, New York, NY, USA, 1980.

[12] I. G. Denisov, T. M. Makris, S. G. Sligar, and I. Schlichting, "Structure and chemistry of cytochrome P450," Chemical Reviews, vol. 105, no. 6, pp. 2253-2277, 2005.

[13] I. C. Gunsalus, T. C. Pederson, and S. G. Sligar, "Oxygenasecatalyzed biological hydroxylations," Annual Review of Biochemistry, vol. 44, pp. 377-407, 1975.

[14] R. I. Kureshy, N. H. Khan, S. H. R. Abdi, and P. Iyer, "Chiral Ru(III) metal complex-catalyzed aerobic enantioselective epoxidation of styrene derivatives with co-oxidation of aldehyde," Journal of Molecular Catalysis A, vol. 124, no. 2-3, pp. 91-97, 1997.

[15] W. H. Leung and C. M. Che, "Oxidation chemistry of ruthenium-salen complexes," Inorganic Chemistry, vol. 28, no. 26, pp. 4619-4622, 1989.

[16] A. M. El-Hendawy, A. H. Alkubaisi, A. E. G. El-Kourashy, and M. M. Shanab, "Ruthenium(II) Complexes of O,N-donor Schiff base ligands and their use as catalytic organic oxidants," Polyhedron, vol. 12, no. 19, pp. 2343-2350, 1993. 
[17] L. Salmon, C. Bied-Charreton, A. Gaudemer, P. Moisy, F. Bedioui, and J. Devynck, "Structural studies of metalloporphyrins. 9. "Looping-over" cobalt porphyrins: coordinating properties and application to dioxygen fixation and activation," Inorganic Chemistry, vol. 29, no. 15, pp. 2734-2740, 1990.

[18] L. Gaillon, N. Sajot, F. Bedioui, J. Devynck, and K. J. Balkus, "Electrochemistry of zeolite-encapsulated complexes. Part 3. Characterization of iron and manganese SALEN entrapped in Y faujasite type zeolite," Journal of Electroanalytical Chemistry, vol. 345, no. 1-2, pp. 157-167, 1993.

[19] H. Nishihara, K. Pressprich, R. W. Murray, and J. P. Collman, "Electrochemical olefin epoxidation with manganese mesotetraphenylporphyrin catalyst and hydrogen peroxide generation at polymer-coated electrodes," Inorganic Chemistry, vol. 29, no. 5, pp. 1000-1006, 1990.

[20] S. F. Tan, P. H. Leung, and W. C. Sin, "Catalytic autooxidation of p-anisaldehyde and styrene by a cobalt bis-schiff base complex," Transition Metal Chemistry, vol. 16, no. 5, pp. 542-545, 1991.

[21] C. P. Horwitz, S. E. Creager, and R. W. Murray, "Electrocatalytic olefin epoxidation using manganese Schiff-base complexes and dioxygen," Inorganic Chemistry, vol. 29, no. 5, pp. 1006-1011, 1990.

[22] J. C. Moutet and A. Ourari, "Electrocatalytic epoxidation and oxidation with dioxygen using manganese(III) Schiffbase complexes," Electrochimica Acta, vol. 42, no. 16, pp. 2525-2531, 1997.

[23] "Etude de deux réactions d'électrocatalyse: Hydrogénation électrocatalytique sur des films de polymères contenant des microparticules de métaux nobles et activation de l'oxygène moléculaire par des complexes de bases de Schiff ", Ph.D. thesis, Joseph Fourrier University, Genoble, France, 1995.

[24] A. Pui, I. Berdan, I. Morgenstern-Badarau, A. Gref, and M. Perrée-Fauvet, "Electrochemical and spectroscopic characterization of new cobalt(II) complexes. Catalytic activity in oxidation reactions by molecular oxygen," Inorganica Chimica Acta, vol. 320, no. 1-2, pp. 167-171, 2001.

[25] J. H. Cameron and S. C. Turner, "Electrochemically controlled dissociation of dioxygen from a $\mu$-peroxo cobalt(III) dimer," Journal of the Chemical Society, Dalton Transactions, no. 23, pp. 3285-3289, 1992.

[26] M. M. T. Khan, S. H. Mehta, A. P. Rao, and K. N. Bhatt, "Electrocatalytic oxidation of organic substrates with oxygen using ruthenium-Schiff base complex," Journal of Molecular Catalysis, vol. 75, no. 3, pp. 245-251, 1992.

[27] R. M. Wang, C. J. Hao, Y. P. Wang, and S. B. Li, "Amino acid Schiff base complex catalyst for effective oxidation of olefins with molecular oxygen," Journal of Molecular Catalysis A, vol. 147, no. 1-2, pp. 173-178, 1999.

[28] E. Kwiatkowski, G. Romanowski, W. Nowicki, M. Kwiatkowski, and K. Suwińska, "Dioxovanadium(V) Schiff base complexes of N-methyl-1,2-diaminoethane and 2-methyl-1, 2-diaminopropane with aromatic o-hydroxyaldehydes and o-hydroxyketones: synthesis, characterisation, catalytic properties and structure," Polyhedron, vol. 22, no. 7, pp. 1009 1018, 2003.

[29] D. D. Agarwal, R. P. Bhatnagar, R. Jain, and S. Srivastava, "Epoxidation of olefins catalysed by Fe(III) Schiff base complexes as catalyst," Journal of Molecular Catalysis, vol. 59, no. 3, pp. 385-395, 1990.

[30] B. Fisher and R. Eisenberg, "Electrocatalytic reduction of carbon dioxide by using macrocycles of nickel and cobalt," Journal of the American Chemical Society, vol. 102, no. 24, pp. 7361-7363, 1980.
[31] C. E. Dahm and D. G. Peters, "Catalytic reduction of iodoethane and 2-iodopropane at carbon electrodes coated with anodically polymerized films of nickel(II) salen," Analytical Chemistry, vol. 66, no. 19, pp. 3117-3123, 1994.

[32] C. E. Dahm and D. G. Peters, "Catalytic reduction of $\alpha, \omega$ dihaloalkanes with nickel(I) salen as a homogeneous-phase and polymer-bound mediator," Journal of Electroanalytical Chemistry, vol. 406, no. 1-2, pp. 119-129, 1996.

[33] R. Zhang, J. Ma, W. Wang, B. Wang, and R. Li, "Zeoliteencapsulated $\mathrm{M}(\mathrm{Co}, \mathrm{Fe}, \mathrm{Mn})(\mathrm{SALEN})$ complexes modified glassy carbon electrodes and their application in oxygen reduction," Journal of Electroanalytical Chemistry, vol. 643, no. 1-2, pp. 31-38, 2010.

[34] B. Tyagi, B. Shaik, and H. C. Bajaj, "Epoxidation of styrene with molecular $\mathrm{O}^{2}$ over sulfated $\mathrm{Y}-\mathrm{ZrO}^{2}$ based solid catalysts," Applied Catalysis A, vol. 383, no. 1-2, pp. 161-168, 2010.

[35] P. Guo and K. Y. Wong, "Enantioselective electrocatalytic epoxidation of olefins by chiral manganese Schiff-base complexes," Electrochemistry Communications, vol. 1, no. 11, pp. 559-563, 1999.

[36] F. Bedioui, E. De Boysson, J. Devynck, and K. J. Balkus, "Electrochemistry of zeolite-encapsulated cobalt salen complexes in acetonitrile and dimethyl sulphoxide solutions," Journal of the Chemical Society, Faraday Transactions, vol. 87, no. 24, pp. 3831-3834, 1991.

[37] G. N. Vyas and N. M. Shah, "Quinacetophenone monomethyl ether," Organic Syntheses, Coll., vol. 4, p. 886, 1963.

[38] A. Anthonysamy and S. Balasubramanian, "Synthesis, spectral, thermal and electrochemical studies of nickel (II) complexes with NO donor ligands," Inorganic Chemistry Communications, vol. 8, no. 10, pp. 908-911, 2005.

[39] M. Yuasa, T. Nagaiwa, M. Kato, I. Sekine, and S. Hayashi, "Electrochemical properties of metalloporphyrin-clay complex-modified electrode systems: investigation as oxygen sensors," Journal of the Electrochemical Society, vol. 142, no. 8, pp. 2612-2617, 1995.

[40] I. Sasaki, D. Pujol, and A. Gaudemer, "Non-symmetric Schiff base Co(II) complexes. Synthesis and catalytic activity in the oxidation of 2,6-Di-tert-butylphenol by molecular oxygen," Inorganica Chimica Acta, vol. 134, no. 1, pp. 53-57, 1987.

[41] Y. W. Liou and C. M. Wang, "Peroxidase mimicking: $\mathrm{Fe}$ (Salen)Cl modified electrodes, fundamental properties and applications for biosensing," Journal of Electroanalytical Chemistry, vol. 481, no. 1, pp. 102-109, 2000.

[42] J. Losada, I. del Peso, L. Beyer, J. Hartung, V. Fernández, and M. Möbius, "Electrocatalytic reduction of $\mathrm{O}$ and $\mathrm{CO}$ with electropolymerized films of polypyrrole cobalt(II) Schiff-base complexes," Journal of Electroanalytical Chemistry, vol. 398, no. 1-2, pp. 89-93, 1995.

[43] P. N. Barlett and J. M. Cooper, "A review of the immobilization of enzymes in electropolymerized films," Journal of Electroanalytical Chemistry, vol. 362, no. 1-2, pp. 1-12, 1993.

[44] W. Schuhmann, "Conducting polymer based amperometric enzyme electrodes," Mikrochimica Acta, vol. 121, no. 1-4, pp. 1-29, 1995.

[45] S. Cosnier, A. Lepellec, B. Guidetti, and I. Rico-Lattes, "Enhancement of biosensor sensitivity in aqueous and organic solvents usinga combination of poly(pyrrole-ammonium) and poly(pyrrole-lactobionamide) filmsas host matrices," Journal of Electroanalytical Chemistry, vol. 449, no. 1-2, pp. 165-171, 1998.

[46] G. Cauquis, S. Cosnier, A. Deronzier et al., "Poly(pyrrolemanganese porphyrin): a catalytic electrode material as a model system for olefin epoxidation and drug metabolism 
with molecular oxygen," Journal of Electroanalytical Chemistry, vol. 352, no. 1-2, pp. 181-195, 1993.

[47] M. M. Taqui Khan, N. H. Khan, R. I. Kureshy, A. B. Boricha, and Z. A. Shaikh, "Synthesis, characterisation, oxygenation and carbonylation of ruthenium(III) schiff base complexes," Inorganica Chimica Acta, vol. 170, no. 2, pp. 213-223, 1990.

[48] T. Katsuki, "Some recent advances in metallosalen chemistry," Synlett, no. 3, pp. 281-297, 2003.

[49] P. G. Cozzi, "Metal-Salen Schiff base complexes in catalysis: practical aspects," Chemical Society Reviews, vol. 33, no. 7, pp. 410-421, 2004.

[50] J. Sanmartín, M. R. Bermejo, A. M. Garía-Deibe, M. Maneiro, C. Lage, and A. J. Costa-Filho, "Mono- and polynuclear complexes of $\mathrm{Fe}(\mathrm{II}), \mathrm{Co}(\mathrm{II}), \mathrm{Ni}(\mathrm{II}), \mathrm{Cu}(\mathrm{II}), \mathrm{Zn}(\mathrm{II})$ and Cd(II) with N,N'-bis(3-hydroxysalicylidene)-1,3-diamino-2propanol," Polyhedron, vol. 19, no. 2, pp. 185-192, 2000.

[51] P. Gili, M. G. Martin Reyes, P. Martin Zarza et al., "Synthesis, spectroscopic, magnetic and electrochemical properties of $\mathrm{Cu}(\mathrm{II})$ and $\mathrm{Fe}(\mathrm{III})$ complexes with the new ligand $\mathrm{N}, \mathrm{N}$ '[1,1'-dithiobis (phenyl)]bis (5'-methoxysalicylaldimine)," Inorganica Chimica Acta, vol. 244, no. 1, pp. 25-36, 1996.

[52] L. J. Bellamy, The Infrared Spectra of Complex Molecules, Chapman and Hall, London, UK, 3rd edition, 1975.

[53] P. Gili, M. G. Martín Reyes, P. Martín Zarza, M. F. C. Guedes Da Silva, Y. Y. Tong, and A. J. L. Pombeiro, "Complexes of $\mathrm{Mn}(\mathrm{II})$ and $\mathrm{Mn}$ (III) with the Schiff base $\mathrm{N}$-[2-(3ethylindole)]pyridoxaldimine. Electrochemical study of these and related $\mathrm{Ni}(\mathrm{II})$ and $\mathrm{Cu}(\mathrm{II})$ complexes," Inorganica Chimica Acta, vol. 255, no. 2, pp. 279-288, 1997.

[54] A. Vogt, S. Wołowiec, R. L. Prasad, A. Gupta, and J. Skarzewski, "Synthesis and characterization of nickel(II), copper(II), manganese(III) and iron(III) complexes with new chiral salentype ligand $\mathrm{N}, \mathrm{N}$ '-bis(3,5-di-tert-butylsalicylidene)-(1R,3S)1,3-diamine-1,2,2- trimethylcyclopentane," Polyhedron, vol. 17, no. 8, pp. 1231-1240, 1998.

[55] Z. Cimerman, N. Galic, and B. Bosner, "The Schiff bases of salicylaldehyde and aminopyridines as highly sensitive analytical reagents," Analytica Chimica Acta, vol. 343, no. 1-2, pp. 145-153, 1997.

[56] A. B. P. Lever, Inorganic Electronic Spectroscopy, Elsevier, London, UK, 2nd edition, 1992.

[57] S. Djebbar-Sid, O. Benali-Baitich, and J. P. Deloume, "Synthesis, characterization and electrochemical behaviour of cobalt(II) and cobalt(III):O complexes, respectively, with linear and tripodal tetradentate ligands derived from Schiff bases," Journal of Molecular Structure, vol. 569, no. 1-3, pp. 121-128, 2001.

[58] T. W. Hambley, C. J. Hawkins, and T. A. Kabanos, "Synthetic, structural, and physical studies of tris(2,4-pentanedionato)vanadium(IV) hexachloroantimonate(V) and tris(1phenyl-1,3-butanedionato)vanadium(IV) hexachloro-antimonate(V)," Inorganic Chemistry, vol. 26, no. 22, pp. 3740-3745, 1987.

[59] C. J. Hawkins and T. A. Kabanos, "Synthesis and characterization of (catecholato)bis( $\beta$-diketonato)vanadium(IV) complexes," Inorganic Chemistry, vol. 28, no. 6, pp. 1084-1087, 1989.

[60] D. T. Sawyer, M. J. Gibian, M. M. Morrison, and E. T. Seo, "On the chemical reactivity of superoxide ion," Journal of the American Chemical Society, vol. 100, no. 2, pp. 627-628, 1978.

[61] R. S. Nicholson and I. Shain, "Theory of stationary electrode polarography single scan and cyclic methods applied to reversible, irreversible, and kinetic systems," Analytical Chemistry, vol. 36, no. 4, pp. 706-723, 1964.
[62] C. Evans, G. J. Harfoot, J. S. McIndoe et al., "The preparation and characterisation of monomeric and linked metal carbonyl clusters containing the closo-SiCo pseudo-octahedral core," Journal of the Chemical Society. Dalton Transactions, no. 24, pp. 4678-4683, 2002.

[63] A. Ourari, K. Ouari, M. A. Khan, and G. Bouet, "Dioxygen activation with a cytochrome P450 model. Characterization and electrochemical study of new unsymmetrical tetradentate Schiff-base complexes with iron(III) and cobalt(II)," Journal of Coordination Chemistry, vol. 61, no. 23, pp. 3846-3859, 2008.

[64] J. P. Collman, M. Marrocco, P. Denisevich, C. Koval, and F. C. Anson, "Potent catalysis of the electroreduction of oxygen to water by dicobalt porphyrin dimers adsorbed on graphite electrodes," Journal of Electroanalytical Chemistry, vol. 101, no. 1, pp. 117-122, 1979.

[65] J. P. Collman, P. Denisevich, Y. Konai, M. Marrocco, C. Koval, and F. C. Anson, "Electrode catalysis of the fourelectron reduction of oxygen to water by dicobalt face-to-face porphyrins," Journal of the American Chemical Society, vol. 102, no. 19, pp. 6027-6036, 1980.

[66] R. R. Durand, C. S. Bencosme, J. P. Collman, and F. C. Anson, "Mechanistic aspects of the catalytic reduction of dioxygen by cofacial metalloporphyrins," Journal of the American Chemical Society, vol. 105, no. 9, pp. 2710-2718, 1983.

[67] H. Y. Liu, I. Abdalmuhdi, C. K. Chang, and F. C. Anson, "Catalysis of the electroreduction of dioxygen and hydrogen peroxide by an anthracene-linked dimeric cobalt porphyrin," Journal of Physical Chemistry, vol. 89, no. 4, pp. 665-670, 1985.

[68] H. Y. Liu, M. J. Weaver, C. B. Wang, and C. K. Chang, "Dependence of electrocatalysis for oxygen reduction by adsorbed dicobalt cofacial porphyrins upon catalyst structure," Journal of Electroanalytical Chemistry, vol. 145, no. 2, pp. 439-447, 1983.

[69] C. K. Chang, H. Y. Liu, and I. Abdalmuhdi, "Electroreduction of oxygen by pillared cobalt cofacial diporphyrin catalysts," Journal of the American Chemical Society, vol. 106, no. 9, pp. 2725-2726, 1984.

[70] K. M. Kadish, C. Araullo-McAdams, B. C. Han, and M. M. Franzen, "Syntheses and spectroscopic characterization of (T(P-MeN)FPP $) \mathrm{H}$ and $(7(\mathrm{p}-\mathrm{MeN}) \mathrm{FPP}) \mathrm{M}$ where $7(\mathrm{p}-\mathrm{MeN}) \mathrm{FPP}$ is the dianion of meso-tetrakis(o,o,w,wtetrafluoro-p-(dimethylamino)phenyl)-porphyrin and $\mathrm{M}=$ $\mathrm{Co}(\mathrm{II}), \mathrm{Cu}(\mathrm{II})$, or $\mathrm{Ni}(\mathrm{II})$," Journal of the American Chemical Society, vol. 112, no. 23, pp. 8364-8368, 1990.

[71] T. G. Traylor, Y. S. Byun, P. S. Traylor, P. Battioni, and D. Mansuy, "Polymeric polyhalogeneted metallopophyrin catalysts for hydroxylation of alkanes and epoxidation of alkenes," Journal of the American Chemical Society, vol. 113, no. 20, pp. 7821-7823, 1991.

[72] P. K. S. Tsang and D. T. Sawyer, "Electron-transfer thermodynamics and bonding for the superoxide $(\mathrm{O})$, dioxygen $(\mathrm{O})$, and hydroxyl $(\mathrm{OH})$ adducts of (tetrakis(2,6-dichlorophenyl)porphinato)iron, -manganese, and -cobalt in dimethylformamide," Inorganic Chemistry, vol. 29, no. 15, pp. 2848-2855, 1990. 


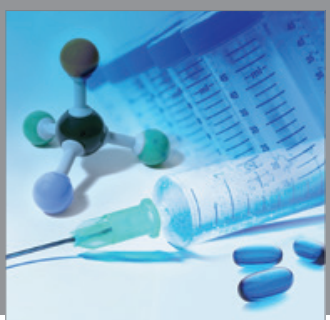

International Journal of

Medicinal Chemistry

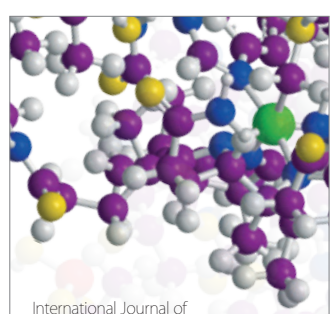

Carbohydrate Chemistry

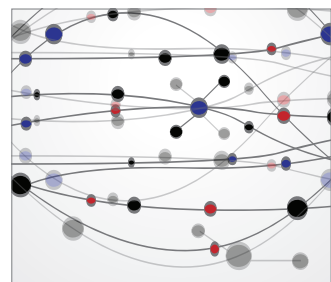

The Scientific World Journal
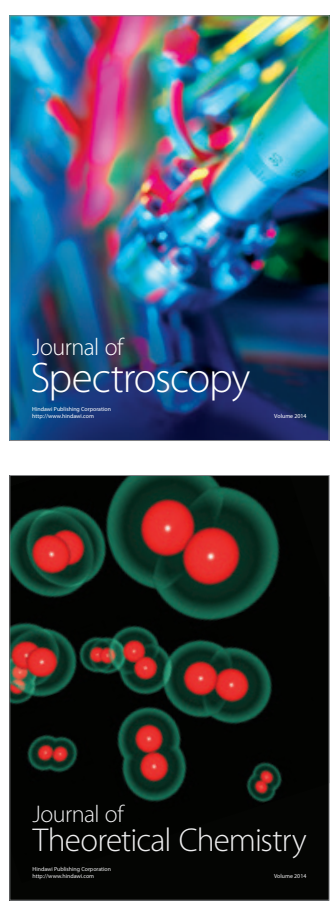
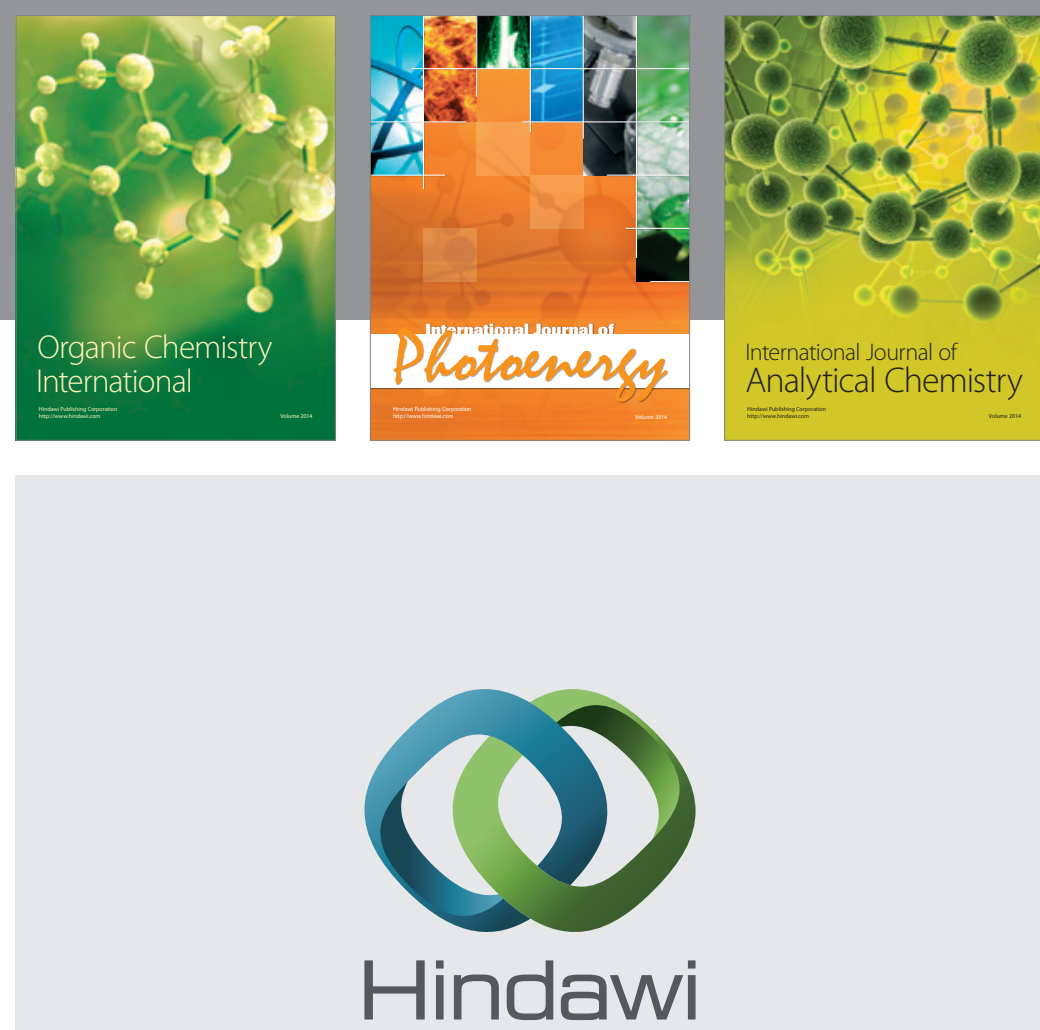

Submit your manuscripts at

http://www.hindawi.com
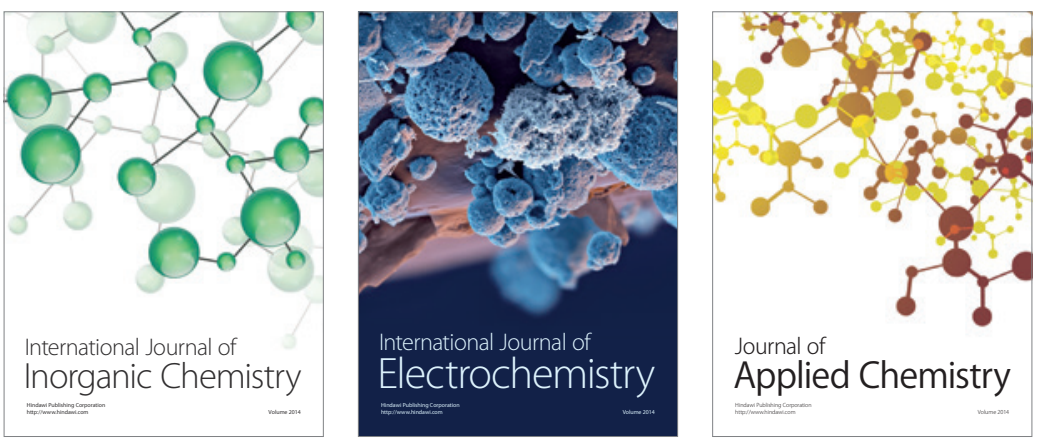

Journal of

Applied Chemistry
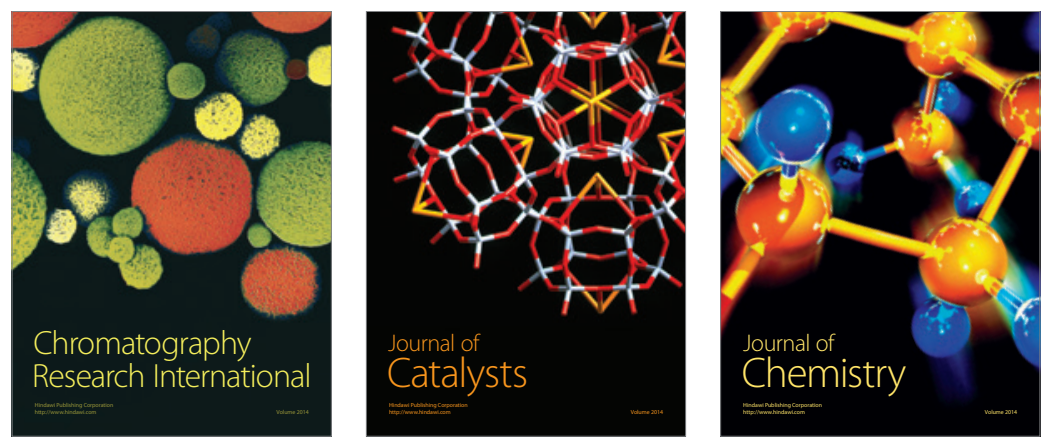
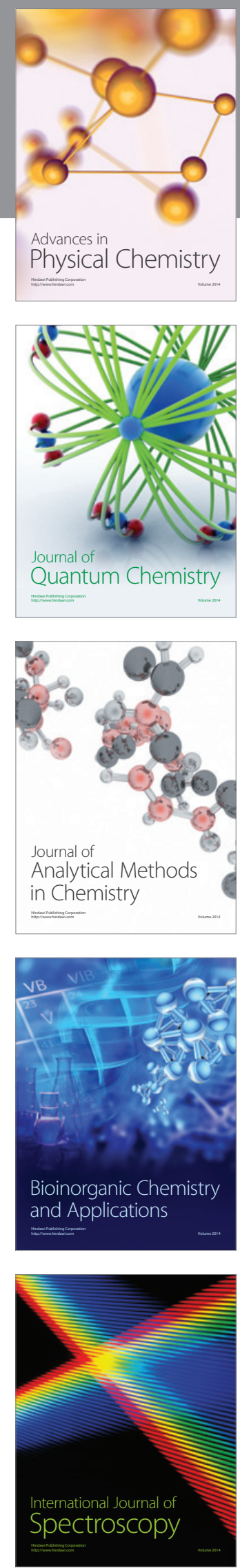